\title{
Neurotoxic Effects of Fluorinated Glucocorticoid Preparations on the Developing Mouse Brain: Role of Preservatives
}

\author{
OLIVIER BAUD, VINCENT LAUDENBACH, PHILIPPE EVRARD, AND PIERRE GRESSENS
}

INSERM E 9935 and Service de Neurologie Pédiatrique, Hôpital Robert-Debré, F-75019 Paris, France

\begin{abstract}
Prenatal betamethasone (Celestene) therapy reduces the incidence of brain damage, whereas prenatal or neonatal dexamethasone (Soludecadron) increases the risk of brain lesions or neuromotor deficits. To determine whether this increase is ascribable to the sulfites used as preservatives in Soludecadron, we investigated the effects of $12 \mathrm{~h}$ of exposure to pure dexamethasone, Soludecadron, pure betamethasone, Celestene, and sulfites on in vitro and in vivo death of neurons cultured under basal conditions or with excitotoxic agents ( $N$-methyl-D-aspartate or (S)-5-bromowillardiine) or hypoxia. Apoptotic features were quantitated using a fluorescent chromatin stain (Hoechst 33258). Neuronal viability was unaffected by pure dexamethasone, pure betamethasone, or Celestene. Soludecadron or sulfites significantly increased neuronal loss. Pure dexamethasone or pure betamethasone produced a $40-50 \%$ decrease in neuronal death induced by $N$-methyl-D-aspartate, $(S)$-5-bromowillardiine, or hypoxia, whereas Soludecadron had no effect and sulfites signif-
\end{abstract}

ABSTRACT

icantly increased the neurotoxicity of excitotoxic agents. In in vivo experiments involving terminal deoxynucleotidyl transferase-mediated dUTP nick-end labeling after several i.p. injections of fluorinated glucocorticoids, Soludecadron, but not pure dexamethasone, significantly increased the number of terminal deoxynucleotidyl transferase-mediated dUTP nick-end labelingstained cells in neocortical layers and thalamus. These experimental findings suggest that injectable dexamethasone should be used with caution during the perinatal period. (Pediatr Res 50: 706-711, 2001)

\section{Abbreviations}

MEM, minimum Eagle medium

NMDA, $N$-methyl-D-aspartate

TUNEL, terminal deoxynucleotidyl transferase-mediated dUTP nick-end labeling

$\mathbf{P}$, postnatal day
Despite substantial improvements in neonatal mortality and morbidity, the rate of cerebral palsy per 1000 live births has not decreased during the last 20 y (1). Severe disability has been reported in $49 \%$ of children with a history of extreme prematurity (2). The relationship between cerebral palsy and the location of brain damage remains controversial. However, in addition to white matter lesions usually observed, a central role for cortical neuronal dysfunction has been suggested (3). Experimental data suggest that the brain lesions associated with cerebral palsy may be related to excitotoxic phenomena induced by hypoxic-ischemic insults or other causes of glutamate receptor overactivation (4-7).

Administration of dexamethasone early or later after birth to prevent or treat severe bronchopulmonary dysplasia in preterm infants has been found to increase the risk of brain lesions or neuromotor deficits $(8-11)$. On the other hand, since the study

Received March 9, 2001; accepted August 7, 2001.

Correspondence and reprint requests: Pierre Gressens, M.D., INSERM E 9935, Hôpital Robert-Debré, 48 Bd Sérurier, 75019 Paris, France; E-mail: gressens@idf.inserm.fr

Supported by the INSERM, the Assistance Publique des Hôpitaux de Paris, and the Fondation Grace de Monaco. by Liggins and Howie (12), several randomized trials and meta-analyses have shown that glucocorticoids given to women at risk for premature labor reduce neonatal mortality and morbidity (13). The two major neonatal benefits of prenatal corticosteroid therapy are acceleration of in utero lung development (reducing the risk of respiratory distress syndrome) and prevention of intraventricular bleeding. Betamethasone and dexamethasone are the only two pharmacologically effective fluorinated glucocorticoids used in humans. There is no convincing evidence that one is superior over the other.

The potential influence of prenatal glucocorticoid therapy on cerebral injury has not been studied until recently $(14,15)$. In these studies, prenatal betamethasone was associated with a reduced incidence of periventricular leukomalacia in a cohort of very premature infants, whereas prenatal dexamethasone was associated with a greater risk of periventricular leukomalacia compared with neonates whose mothers received no glucocorticoids $(14,15)$.

These data suggest that the i.v. dexamethasone preparation (Soludecadron in France) may be associated with an increased 
risk of brain lesions or neurologic disabilities. However, the molecular mechanisms of the potential neurotoxic effect of Soludecadron remain unknown. The methyl group at position 16 is in the alpha configuration in dexamethasone and in the beta configuration in betamethasone. This structural difference might affect the pharmacologic activities of the two molecules and their interactions with receptors such as the glutamate receptor (16). Alternatively, the sulfites used as preservatives in i.v. dexamethasone preparations throughout the world ( $0.155 \mathrm{mg}$ sulfites $/ \mathrm{mg}$ of dexamethasone in Soludecadron) may be neurotoxic. Neurotoxicity has been demonstrated with sulfites in supraphysiologic concentrations (17). This was exacerbated by oxygen radicals (such as peroxynitrites) produced during inflammation or hypoxia-ischemia (17).

The goal of the present study was to investigate the potential neurotoxic effects of fluorinated corticosteroid preparations and to evaluate the role played by sulfites in in vitro and in vivo models of neuronal cell death.

\section{METHODS}

All experimental protocols complied with the guidelines issued by the Institut National de la Santé et de la Recherche Médicale (INSERM) and were approved by our institutional review board.

\section{In Vitro Experiments}

Neuronal cultures. Primary cortical neurons were obtained from mouse embryos at $14.5 \mathrm{~d}$ embryonic age, as previously described (18). Briefly, the embryos were harvested from anesthetized pregnant dams. The embryo brains were removed, and the cortex was dissected and subjected to enzymatic (trypsin $0.25 \%$, DNase) and mechanical dissociation. Then, the neurons were plated out in 35-mm dishes coated with poly-DLornithine (Sigma Chemical Co., St. Louis, MO, U.S.A.), in a concentration of $8 \times 10^{5}$ neurons per dish, with MEM (Life Technologies, Cergy-Pontoise, France) enriched with 10\% horse serum. Also, some neurons were plated out on coverslips, which were transferred to a glial cell culture for analysis of cell-cell interactions. Four hours after plating, MEM was replaced by Neurobasal medium (Life Technologies) supplemented with $2 \mathrm{mM}$ glutamine and B27 (Life Technologies). Cultures were maintained at $37^{\circ} \mathrm{C}$ in a humidified $5 \% \mathrm{CO}_{2}$ atmosphere. After 3 to $6 \mathrm{~d}$, nonneuronal cell growth was blocked by addition of $5 \times 10^{-6} \mathrm{M}$ cytosine arabinoside. Only mature cultures (10 to $12 \mathrm{~d}$ in vitro) were used for the experiments.

Astroglial cultures. Astrocytes were obtained from mice aged $0-2 \mathrm{~d}$, as previously described (19). The procedure was the same as for neurons, except that the dissociation product was centrifuged $(450 \times g, 10 \mathrm{~min})$ to pellet nonneuronal cells. Confluent cultures, usually obtained 15 to $20 \mathrm{~d}$ after plating, were used. During the proliferation stage, the cells were kept in MEM with $10 \%$ horse serum. In cocultures, MEM-10\% horse serum was replaced by Neurobasal + B27 when neuronbearing coverslips were put in contact with astroglial cells.

Effect of glucocorticoids and sodium metabisulfite on neuronal and astroglial cell death. Pure neuronal cultures or neuronoglial cocultures were incubated in 0.1 to $100 \mu \mathrm{M}$ injectable dexamethasone (Soludecadron; Merck Sharp, Paris, France), injectable betamethasone (Celestene; ScheringPlough, Levallois-Perret, France), pure dexamethasone (Sigma Chemical Co.), pure betamethasone (Sigma Chemical Co.), sodium metabisulfite (Sigma Chemical Co.), or saline for $12 \mathrm{~h}$. After incubation, the cells were fixed in $4 \%$ paraformaldehyde for $1 \mathrm{~h}$. Chromatin fluorescent staining was performed using 10 $\mu \mathrm{g} / \mathrm{mL}$ bis-benzimide (Hoechst 33258; Sigma Chemical Co.). An observer unaware of the experimental conditions used a fluorescent microscope equipped with an appropriate filter (excitation, $370 \mathrm{~nm}$; emission, $>400 \mathrm{~nm}$ ) to count nuclei with features suggestive of delayed cell death (i.e. pyknosis, chromatin condensation, and fragmentation) in six to 10 randomly selected fields per plate, with 30 to 70 cells per field. The number of apoptotic cells was divided by the total cell number, and for each experimental group, this ratio was normalized to the ratio obtained in controls. Two to three plates were used for each experimental condition. Each experiment was performed at least twice.

Excitotoxic and hypoxic challenges. After preincubation for $4 \mathrm{~h}$ in $0.1-100 \mu \mathrm{M}$ injectable dexamethasone or betamethasone, pure dexamethasone or betamethasone, or sodium metabisulfite (or control), neurons were exposed for $60 \mathrm{~min}$ to 300 $\mu \mathrm{M}$ NMDA (Sigma Chemical Co.) or $200 \mu \mathrm{M}$ (S)-5bromowillardiine (Tocris Cookson, Bristol, UK), a specific agonist of the glutamatergic $\alpha$-amino-3-hydroxy-5-methylisoxazole-4-propionate-kainate receptor. Then the medium was replaced. Eight hours after the beginning of the exposure, the nuclei were stained, and features suggestive of apoptosis were counted (see above). Throughout the experiment, the cells were kept in $95 \%$ air and $5 \% \mathrm{CO}_{2}$ at $37^{\circ} \mathrm{C}$. After the 4-h preincubation with glucocorticoids, sodium metabisulfite, or culture medium alone, some cultures were transferred to an oxygendeprived incubator filled with a humidified mixture of nitrogen $95 \%$ and $\mathrm{CO}_{2} 5 \%$ at $37^{\circ} \mathrm{C}$. After $6 \mathrm{~h}$ under these conditions, the cultures were returned to normoxia. Hypoxia was controlled by analyzing the gas content of the medium (data not shown). Twenty-four hours after hypoxia initiation, the cells were fixed and neuronal cell death was quantified, as described above.

\section{In Vivo Experiments}

Experimental procedures. Female and male Swiss mouse pups from several litters were injected i.p. (final volume, $5 \mu \mathrm{L}$ ) with $1 \mathrm{mg} / \mathrm{kg}$ dexamethasone, $1 \mathrm{mg} / \mathrm{kg}$ Soludecadron, $1 \mathrm{mg} / \mathrm{kg}$ betamethasone, $1 \mathrm{mg} / \mathrm{kg}$ Celestene, or $1 \mathrm{mg} / \mathrm{kg}$ or $10 \mathrm{mg} / \mathrm{kg}$ sodium metabisulfite twice a day on $\mathrm{P} 3$ and $\mathrm{P} 4$, and once on P5. Controls received PBS.

Cell death staining. Eight hours after the last i.p. injection of glucocorticoid, sulfite, or PBS, the pups were decapitated and their brains were fixed in formalin and embedded in paraffin. Cell death was detected using an in situ cell death detection kit (Roche, Meulan, France). Deparaffinized sections were exposed to $20 \mathrm{mg} / \mathrm{mL}$ proteinase $\mathrm{K}$ for $20 \mathrm{~min}$ at $37^{\circ} \mathrm{C}$, then incubated for $2 \mathrm{~min}$ on ice with $0.1 \%$ Triton X-100. DNA strand breaks were identified by labeling of free 3'-OH termini with terminal deoxynucleotidyl transferase and fluorescein- 
labeled nucleotides for $60 \mathrm{~min}$ at $37^{\circ} \mathrm{C}$. Incorporated nucleotides were detected using an anti-fluorescein antibody conjugated with alkaline phosphatase, with nitroblue tetrazolium and 5-bromo-4-chloro-3-indolyl phosphate toluidonium salt as the substrates. Cells stained by TUNEL were counted in a 0.25 $\mathrm{mm}^{2}$ area in the neocortical layers of the paramedian somatosensory cortex, in the underlying white matter, and in the adjacent thalamic area. Sections containing similar anatomic areas were identified in the various experimental groups and treated simultaneously. Ten to 15 nonadjacent fields from five brains were examined in each group.

\section{Statistical Analyses}

Quantitative data were expressed as means \pm SEM for each group. Comparisons were done using ANOVA with Dunnett's or Bonferroni's multiple comparison of means test.

\section{RESULTS}

Effect of glucocorticoids and sulfites on spontaneous in vitro cell death. We analyzed fragmentation of chromatin as a marker of neuronal (Fig. 1) or astrocytic cell death in cultures treated with glucocorticoids or sodium metabisulfite for $12 \mathrm{~h}$.

Exposure of pure neuronal cultures to dexamethasone, betamethasone, or Celestene had no effect on the rate of spontaneous neuronal death compared with PBS (Fig. 2A); in contrast, Soludecadron or sodium metabisulfite caused a dosedependent increase in the rate of neuronal loss (Figs. 1 and 2). Similar results were obtained with neurons cultured in the presence of astrocytes (Fig. $3 A$ ).

Exposure of astrocytes to dexamethasone, betamethasone, Soludecadron, Celestene, or sodium metabisulfite (final concentration, $10 \mu \mathrm{M}$ each) did not significantly modify the rate of astrocyte death as compared with PBS (Fig. 3B).

Effect of glucocorticoids and sulfites on in vitro neuronal cell death induced by hypoxia or excitotoxic agents. Exposure to $300 \mu \mathrm{M}$ NMDA, $200 \mu \mathrm{M}(S)$-5-bromowillardiine, or transient hypoxia induced a significant, 2- to 3 -fold increase in neuronal cell death compared with control cultures (Fig. 4). Pretreatment with $10 \mu \mathrm{M}$ dexamethasone, betamethasone, or Celestene led to a $40-50 \%$ decrease in spontaneous neuronal death induced by NMDA, $(S)$-5-bromowillardiine, or hypoxia alone (Fig. 4). In contrast, $10 \mu \mathrm{M}$ Soludecadron did not decrease neuronal cell death induced by these insults (Fig. 4). Finally, $10 \mu \mathrm{M}$ sodium metabisulfite significantly increased the neurotoxic effect of the excitotoxic agents, but not of hypoxia (Fig. 4).

Effect of glucocorticoids and sulfites on physiologic in vivo neuronal cell death. To test the potential effects of glucocorticoids and sodium metabisulfite on in vivo developmental neural cell death, TUNEL (Fig. 5) was used to examine specimens obtained on P5 from animals that had received several i.p. injections of the agents under study or of PBS. Dexamethasone, betamethasone, Celestene, and sulfites had no detectable effects on gray or white matter cell death (Fig. 6). In contrast, Soludecadron significantly increased neuronal cell death in both the cortical plate and the thalamus without modifying the rate of white matter cell death compared with
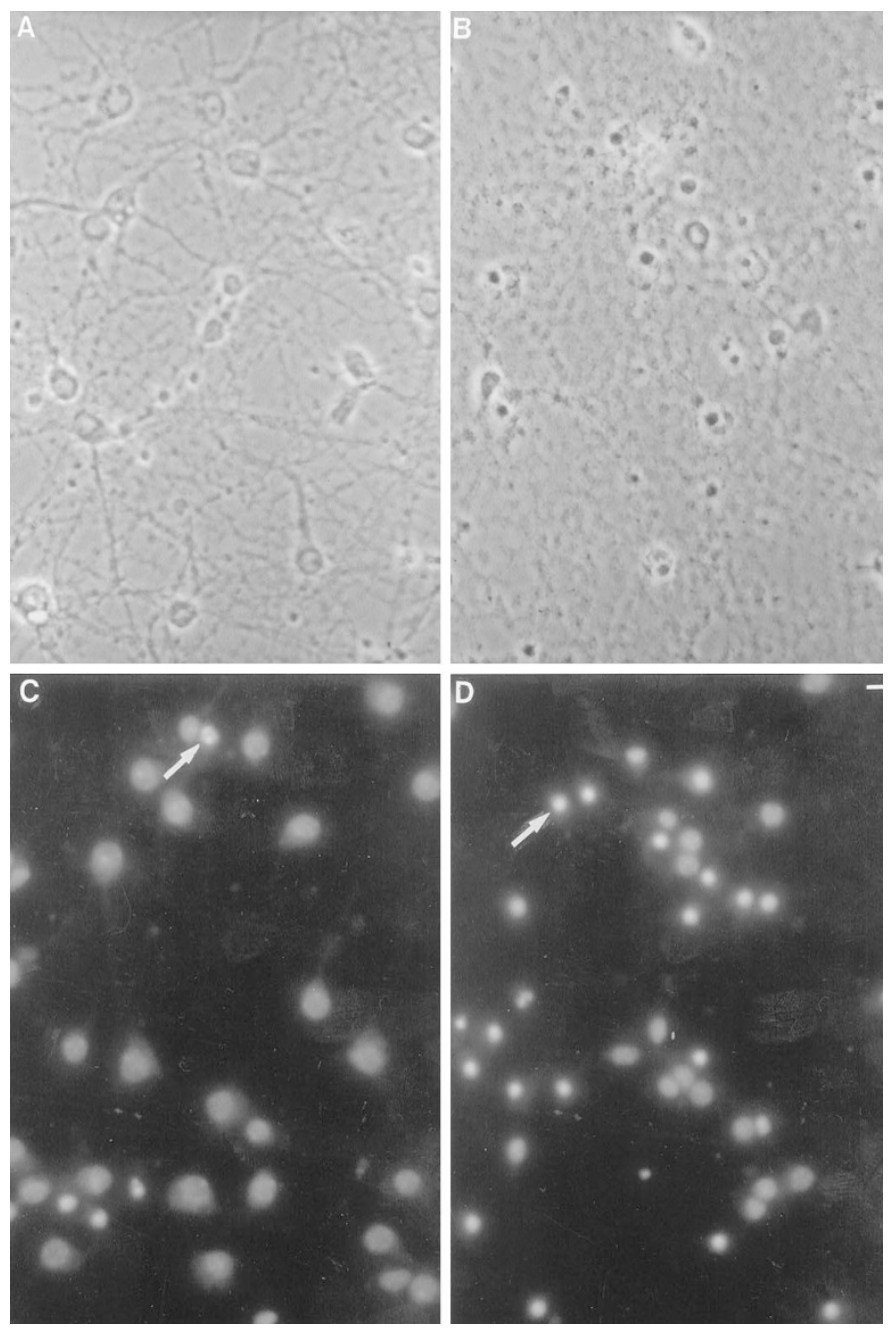

Figure 1. Typical photomicrographs of cultured neurons exposed to medium $(A, C)$ or $10^{-5} \mathrm{M}$ Soludecadron $(B, D)$ for $12 \mathrm{~h}$. Cells were examined under the microscope without staining $(A, B)$ or after chromatin staining with bisbenzimide (Hoechst 33258; $C, D$ ). Arrows point to examples of nuclei showing apoptotic features. Bar $=25 \mu \mathrm{m}$.

controls (Figs. 5 and 6). Although there was some intersample variability, the analysis of 10 to 15 nonadjacent fields from five separate animals in each experimental group led to homogeneous results (Figs. 5 and 6).

\section{DISCUSSION}

In cultured neurons subjected to excitotoxic or hypoxic insults, pure dexamethasone and betamethasone were neuroprotective, whereas Soludecadron had no significant effect and sodium metabisulfite, a preservative present in Soludecadron, increased the rate of cell death. Furthermore, both sodium metabisulfite and Soludecadron increased spontaneous cell death of cultured neurons. Finally, in vivo, Soludecadron significantly increased the death rate of developing neurons.

Our results are in agreement with the protective effects of betamethasone observed in human premature infants exposed prenatally to betamethasone (15). They provide further support for routine betamethasone therapy in pregnant women at risk for premature delivery. This treatment has shown remarkable 
A

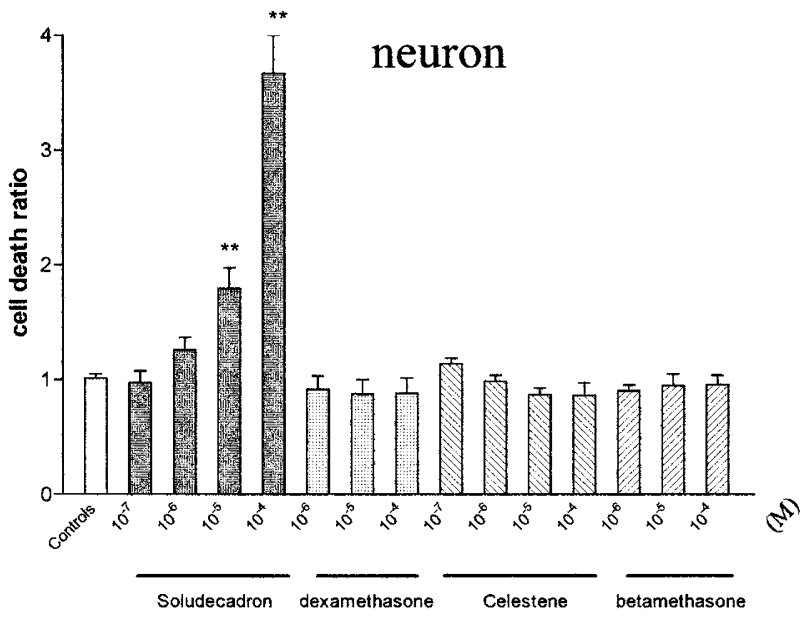

B

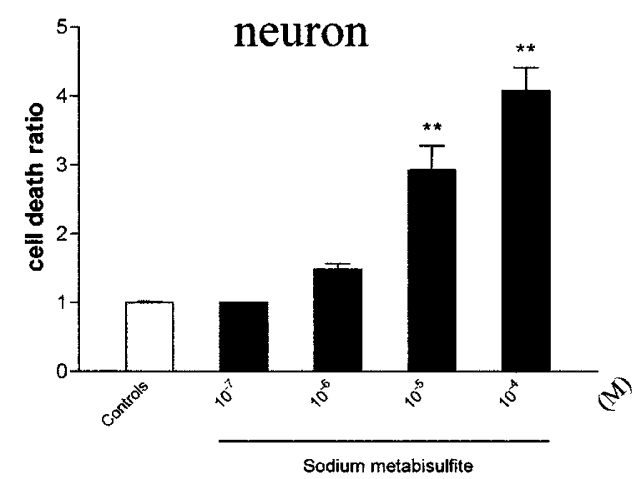

Figure 2. Effect of fluorinated glucocorticoid preparations $(A)$ and sodium metabisulfite $(B)$ on in vitro neuronal cell death. Quantitative analysis of cells showing apoptotic features after staining with bis-benzimide (Hoechst 33258). Number of apoptotic cells was divided by the total cell number, and for each experimental group, this ratio was normalized to the ratio obtained in controls. Results are shown as mean \pm SEM. Asterisks indicate statistically significant differences between control group and experimental groups $(* * p<0.01$ by ANOVA with Dunnett's multiple comparison test).

positive effects on the lung $(13,20)$ and brain $(13)$ of human preterm infants.

The in vitro and in vivo neurotoxic effects of Soludecadron did not seem linked to the glucocorticoid itself, as they were not seen with pure dexamethasone. Several experimental results strongly suggest that this neurotoxicity can be ascribed to the sulfites contained in Soludecadron: 1) as previously mentioned, pure (sulfite-free) dexamethasone did not exhibit toxic effects in the various models studied; 2) the toxicity of Soludecadron for neurons cultured under basal conditions was closely similar to that seen with sodium metabisulfite; and 3) in cells exposed to in vitro excitotoxic or hypoxic challenge, Soludecadron had no neuroprotective or deleterious effects, whereas sodium metabisulfite was toxic, suggesting that with Soludecadron the toxic effects of the sulfites counterbalanced the protective effects of dexamethasone.

At first glance, our in vivo data do not seem to support our working hypothesis of a toxic effect of sodium metabisulfites. Indeed, Soludecadron significantly increased neuronal cell death, whereas sulfites alone did not. However, pure dexamethasone and betamethasone did not replicate the in vivo effects of

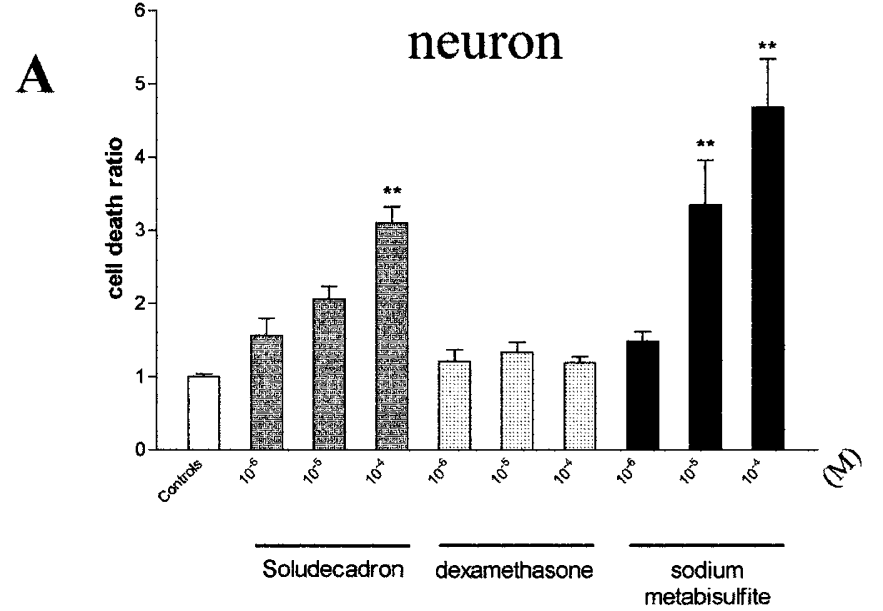

B

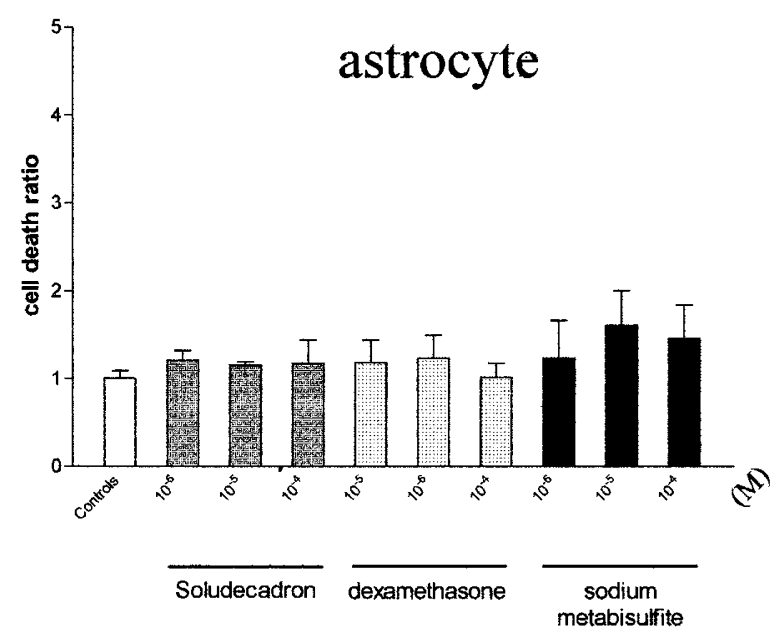

Figure 3. Effect of fluorinated glucocorticoid preparations and sodium metabisulfite on neuronal cell death in cocultures of neurons and astrocytes $(A)$ and on astrocytic cell death in cultures of astrocytes $(B)$. Quantitative analysis of cells showing apoptotic features after staining with bis-benzimide (Hoechst 33258 ). Results are shown as mean \pm SEM. Number of apoptotic cells was divided by the total cell number, and for each experimental group, this ratio was normalized to the ratio obtained in controls. Asterisks indicate statistically significant differences between control group and experimental groups $(* * p<$ 0.01 by ANOVA with Dunnett's multiple comparison of means test).

Soludecadron, again suggesting a deleterious role of the sulfites in Soludecadron. Although this remains to be confirmed, sulfites may be toxic for neurons only in the presence of another metabolic, pharmacologic, or molecular insult. The culture procedure, even in the absence of excitotoxic or hypoxic challenge, is probably a major stress for neurons, and this may explain the toxic effect of pure sulfites in the cell cultures. In contrast, in vivo neurons from healthy P5 pups are not subjected to major stress: this may explain the lack of effect of pure sulfites contrasting with the toxicity of the sulfitedexamethasone combination (Soludecadron) for in vivo neurons. The effects of differences in age, site, or connectivity between in vivo and cultured neurons may also explain the different sulfite effects of sulfites observed in the different experimental paradigms. Further in vivo studies are needed to confirm the role of sulfites in neuronal cell death and in the development of neurologic disabilities. 
A

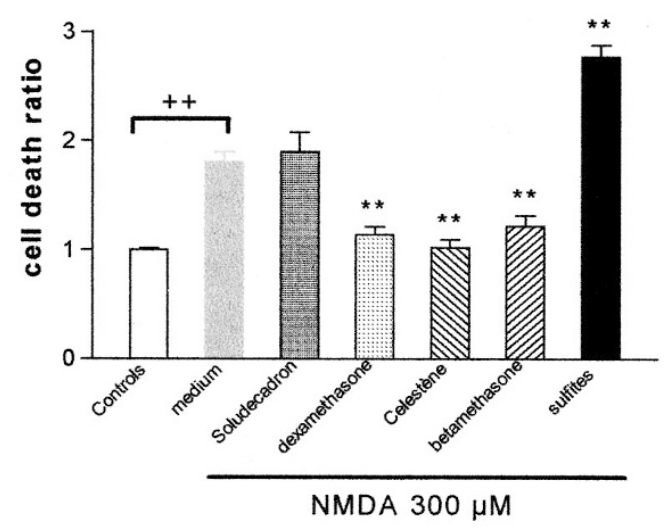

B

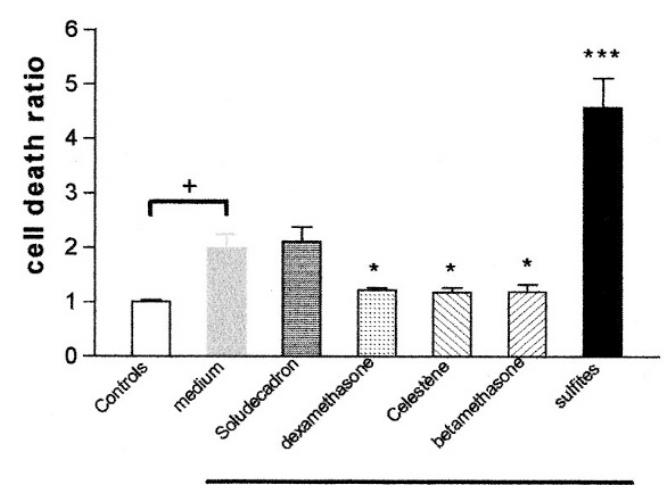

(S)-5-bromowillardiine $200 \mu \mathrm{M}$
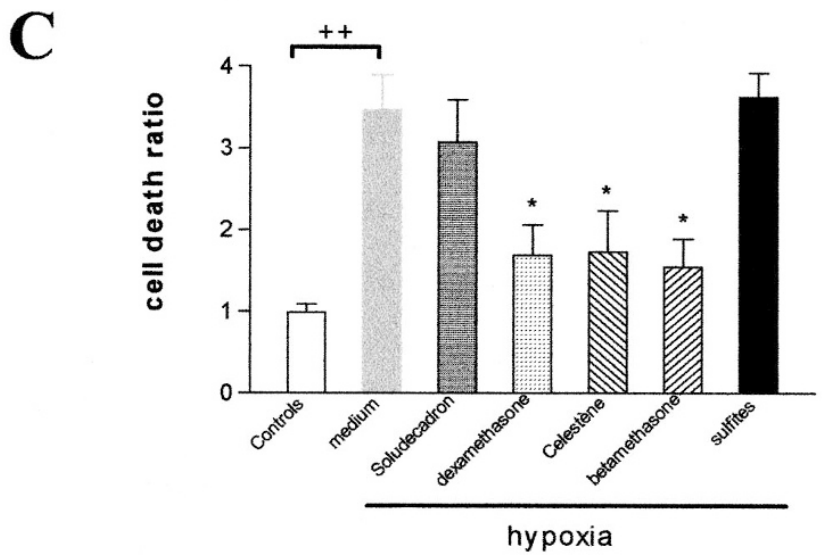

Figure 4. Effect of fluorinated glucocorticoid preparations and sodium metabisulfite $\left(10^{-5} \mathrm{M}\right.$ for all tested compounds) on neuronal cell death induced by NMDA $(A),(S)$-5-bromowillardiine $(B)$, or hypoxia $(C)$. Quantitative analysis of cells showing apoptotic features after staining with bis-benzimide (Hoechst 33258). Number of apoptotic cells was divided by the total cell number, and for each experimental group, this ratio was normalized to the ratio obtained in controls. Results are shown as mean \pm SEM. Asterisks and plus signs indicate statistically significant differences from the medium group $(*)$ or the control group $\left(^{+}\right)\left(^{+}\right.$or $* p<0.05,{ }^{++}$or $* * p<0.01, * * * p<0.01$ by ANOVA with Bonferroni's multiple comparison of means test). Controls are untreated cultures; medium are cultures exposed to an excitotoxic or hypoxic stress but not treated with fluorinated glucocorticoid preparations or sulfites.

In humans, the concentration of fluorinated glucocorticoids in cord blood approximates 0.1 to $0.2 \mu \mathrm{M} 2 \mathrm{~h}$ after administration of these agents to the mother (21). However, this
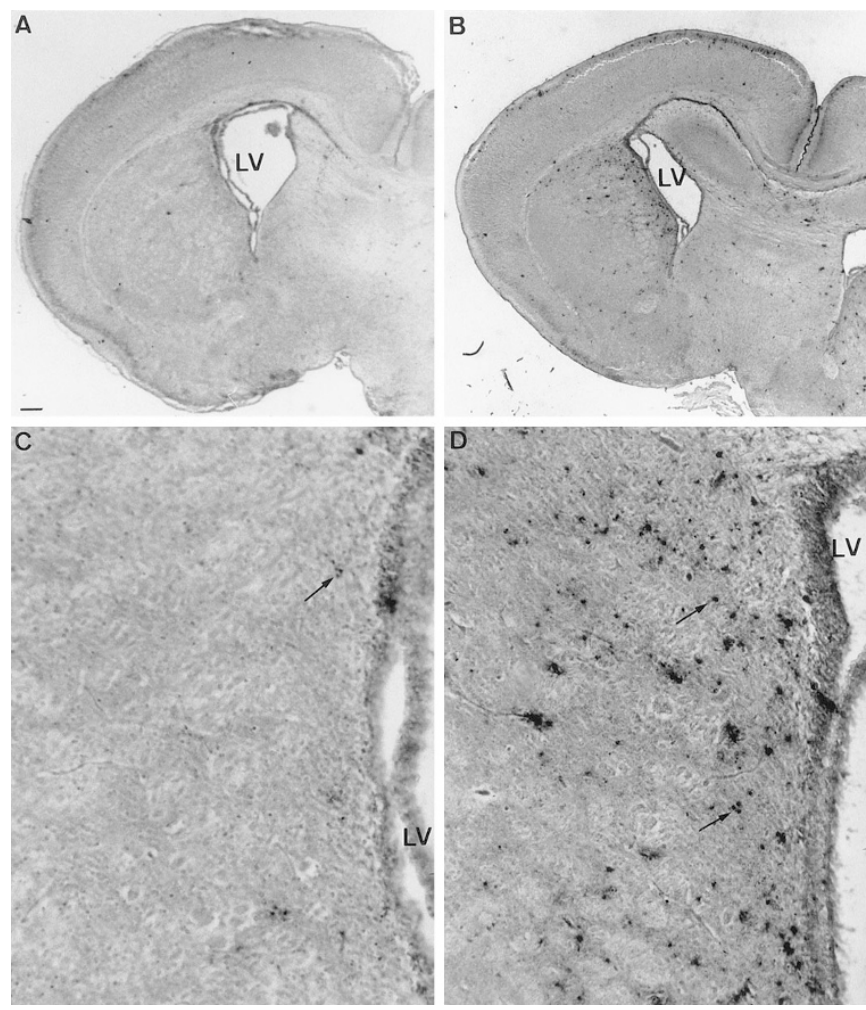

Figure 5. Effects of Soludecadron on in vivo neural cell death. TUNEL staining of coronal sections from pups treated with $\operatorname{PBS}(A, C)$ or $1 \mathrm{mg} / \mathrm{kg}$ per $12 \mathrm{~h}$ Soludecadron $(B, D)$. $C$ and $D$, higher magnifications of $A$ and $B$, respectively, showing the thalamus and lateral ventricle $(L V)$. Arrowheads point to examples of labeled nuclei. $\operatorname{Bar}=250 \mu \mathrm{m}(A, B)$ or $20 \mu \mathrm{m}(C, D)$.

concentration may be higher in very preterm newborns because these infants lose the placental filter at a time when their detoxification systems and renal function are still immature. Therefore, our in vitro results may be relevant to human preterm infants, as the neurotoxic effect of Soludecadron or sulfites became significant from $10 \mu \mathrm{M}$ upward. On the other hand, the doses of glucocorticoids used in the in vivo experiments correspond to about 10 times the dose generally used in pregnant women at risk of preterm delivery. However, these dose and concentration comparisons should be interpreted with caution as metabolic rates may differ between mouse pups and human preterm infants.

Sulfites are widely used as preservatives to prevent microbial or oxidative deterioration of foods and pharmaceutical agents (22). Many secondary effects have been reported after exposure to sulfites. Although most were allergy-related (22), sulfite preservatives have been associated with seizure development when using high doses of i.v. morphine (23). However, the mechanisms of sulfite toxicity for neural cells remain incompletely understood. Cysteine-S-sulfate is a metabolite of sulfites that is structurally very similar to glutamate and other excitotoxic amino acids and may, therefore, share their neurotoxic properties. Also, sulfites induce the production of oxygen and sulfur radicals, which alter nucleic acids, membrane lipids, and proteins. A synergistic action of sulfites with the peroxynitrites produced during hypoxic stress or neurodegenerative diseases has been demonstrated recently in vitro (17). 
A

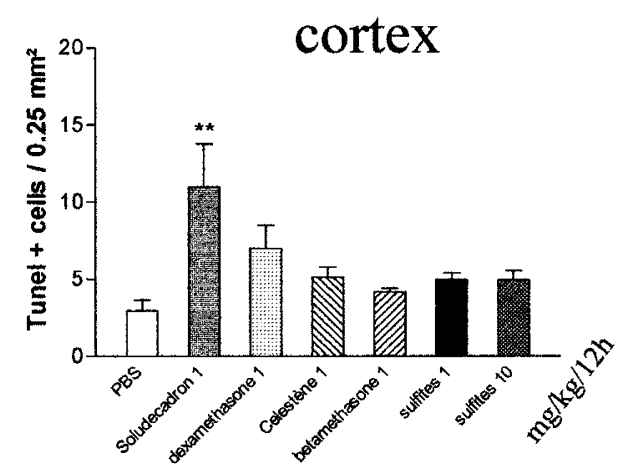

B

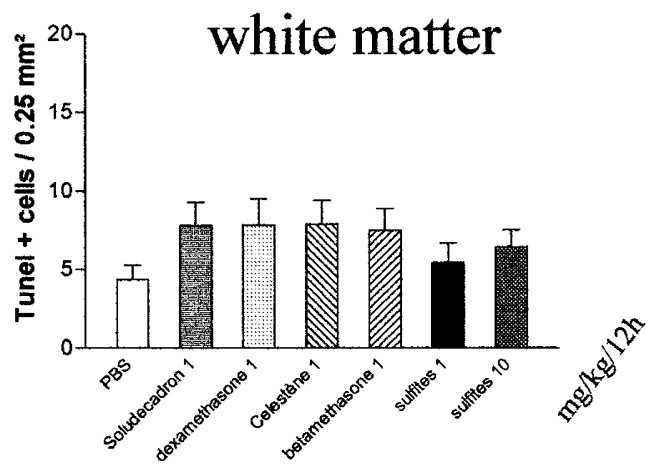

$\mathrm{C}$

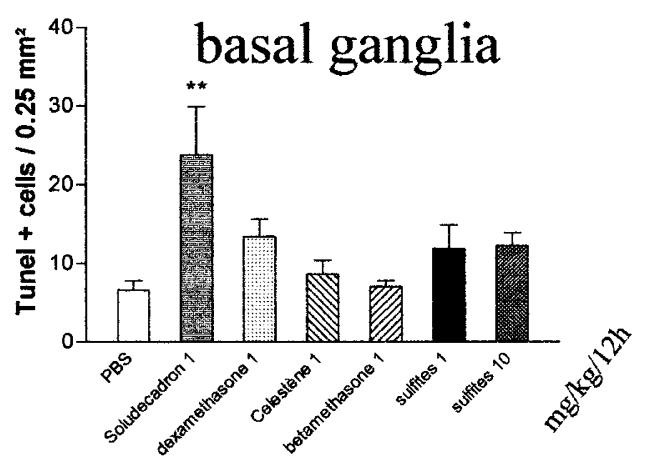

Figure 6. Effect of fluorinated glucocorticoid preparations and sulfites on in vivo neuronal cell death. Quantitative analysis of TUNEL-positive cells in the somatosensory cortical layers $(A)$, underlying white matter $(B)$, and thalamus $(C)$. Values shown are mean \pm SEM. Asterisks indicate statistically significant differences between controls (PBS) and experimental animals $(* * p<0.01$ by ANOVA with Dunnett's multiple comparison of means test).

Several drugs used in neonates contain sulfites as preservatives. The various forms of i.v. dexamethasone on the market in Europe and the United States contain similar amounts of sodium metabisulfite ( 0.25 to $1 \mathrm{mg} / \mathrm{mg}$ of dexamethasone). Other sulfite-containing drugs include vasoactive drugs and ritodrine. Prolonged tocolysis with ritodrine has been associated with an increased risk of either echodense periventricular lesions or cystic white matter damage (24), again suggesting a possible toxic role for sulfites.

In conclusion, the present study showed neuroprotective properties of pure betamethasone, Celestene, and pure dexamethasone. In contrast Soludecadron and sulfites were either inactive or neurotoxic in various experimental settings, supporting previous clinical evidence that i.v. dexamethasone should be used with caution during the perinatal period.

Acknowledgement. We thank the Association des Juniors en Pédiatrie-Laboratoire Gallia for their support in preparing the manuscript.

\section{REFERENCES}

1. Kuban KCK, Leviton A 1994 Cerebral palsy. N Engl J Med 330:188-195

2. Wood NS, Marlow N, Costeloe K, Gibson AT, Wilkinson AR 2000 Neurologic and developmental disability after extremely preterm birth. EPICure Study Group. N Engl J Med 343:378-384

3. Inder TE, Huppi PS, Warfield S, Kikinis R, Zientara GP, Barnes PD, Jolesz F, Volpe JJ 1999 Periventricular white matter injury in the premature infant is followed by reduced cerebral cortical gray matter volume at term. Ann Neurol 46:755-760

4. Marret S, Mukendi R, Gadisseux JF, Gressens P, Evrard P 1995 Effect of ibotenate on brain development: an excitotoxic mouse model of microgyria and post-hypoxiclike lesions. J Neuropathol Exp Neurol 54:358-370

5. Tahraoui SL, Marret S, Bodenant C, Leroux P, Dommergues MA, Evrard P, Gressens P 2001 Central role of microglia in neonatal excitotoxic lesions of the murine periventricular white matter. Brain Pathol 11:56-71

6. Evrard P, Marret S, Gressens P 1997 Excitotoxic cascade and neuroprotection in various stages of cerebral development. Bull Mem Acad R Med Belg 152:159-165

7. McDonald JW, Silverstein FS, Cardona D, Hudson C, Chen R, Johnston MV 1990 Systemic administration of MK- 801 protects against $N$-methyl-D-aspartate- and quisqualate-mediated neurotoxicity in perinatal rats. Neuroscience 36:589-599

8. Yeh TF, Lin YJ, Huang CC, Chen YJ, Lin CH, Lin HC, Hsieh WS, Lien YJ 1998 Early dexamethasone therapy in preterm infants: a follow-up study. Pediatrics 101:e7

9. Baud O, Zupan V, Lacaze-Masmonteil T, Dehan M 1999 Neurological adverse effects of early postnatal dexamethasone therapy in very preterm infants. Arch Dis Child Fetal Neonatal Ed 80:F159

10. Bhuta T, Ohlsson A 1998 Systematic review and meta-analysis of early postnatal dexamethasone for prevention of chronic lung disease. Arch Dis Child Fetal Neonatal Ed 79:F26-F33

11. O'Shea TM, Kothadia JM, Klinepeter KL, Goldstein DJ, Jackson BG, Weaver 3rd RG, Dillard RG 1999 Randomized placebo-controlled trial of a 42-day tapering course of dexamethasone to reduce the duration of ventilator dependency in very low birth weight infants: outcome of study participants at 1 -year adjusted age. Pediatrics 104:15-21

12. Liggins GC, Howie RN 1972 A controlled trial of antepartum glucocorticoid treatment for prevention of the respiratory distress syndrome in premature infants. Pediatrics 50:515-25

13. Crowley P 2000 Prophylactic corticosteroids for preterm birth. Cochrane Database Syst Rev 2:CD000065

14. Baud O, Zupan V, Lacaze-Masmonteil T, Audibert F, Shojaei T, Thebaud B, Ville Y, Frydman R, Dehan M 2000 The relationships between prenatal management, the cause of delivery and neonatal outcome in a large cohort of very preterm singletons. Br J Obstet Gynaecol 107:877-884

15. Baud O, Foix-L'Helias L, Kaminski M, Audibert F, Jarreau PH, Papiernik E, Huon C, Lepercq J, Dehan M, Lacaze-Masmonteil T 1999 Antenatal glucocorticoid treatment and cystic periventricular leukomalacia in very preterm infants. N Engl J Med 341:1990-1996

16. McGowan JE, Sysyn G, Petersson KH, Sadowska GB, Mishra OP, DelivoriaPapadopoulos M, Stonestreet BS 2000 Effect of dexamethasone treatment on maturational changes in the NMDA receptors in sheep brain. J Neurosci 20:7424-7429

17. Reist M, Marshall KA, Jenner P, Halliwell B 1998 Toxic effects of sulfite in combination with peroxynitrite on neuronal cells. J Neurochem 71:2431-2438

18. De Lima AD, Merten MDP, Voigt T 1997 Neuritic differentiation and synaptogenesis in serum-free neuronal cultures of the rat cerebral cortex. J Comp Neurol 382:230 246

19. De Hoop MJ, Meyn L, Dotti CG 1998 Culturing hippocampal neurons and astrocytes from fetal brain. In: Celius JE (ed) Cell Biology, A Laboratory Handbook, 2nd Ed, Vol 1. Academic Press, San Diego, pp 154-164

20. Gamsu HR, Mullinger BM, Donnai P, Dash CH 1989 Antenatal administration of betamethasone to prevent respiratory distress syndrome in preterm infants: report of a UK multicenter trial. Br J Obstet Gynaecol 96:401-410

21. Kream J, Mulay S, Fukushima DK, Solomon S 1983 Determination of plasma dexamethasone in the mother and the newborn after administration of the hormone in a clinical trial. J Clin Endocrinol Metab 56:127-133

22. Walker R 1985 Sulphiting agents in foods: some risk/benefit considerations. Food Addit Contam 2:5-24

23. Meisel SB, Welford PK 1992 Seizures associated with high-dose intravenous morphine containing bisulfite preservative. Ann Pharmacother 26:1515-1517

24. Spinillo A, Capuzzo E, Stronati M, Ometto A, De Santolo A, Acciano S 1998 Obstetric risk factors for periventricular leukomalacia among preterm infants. $\mathrm{Br} \mathrm{J}$ Obstet Gynaecol 105:865-871 